\title{
The effect of administering ketoprofen on the physiology and behavior of dairy cows following surgery to correct a left displaced abomasum
}

\author{
Nathalie C. Newby, ${ }^{*}$ David L. Pearl, ${ }^{*}$ Stephen J. LeBlanc, ${ }^{*}$ Ken E. Leslie, ${ }^{*}$ Marina A. G. von Keyserlingk, $\dagger$ \\ and Todd F. Duffield*1 \\ *Department of Population Medicine, University of Guelph, Guelph, Ontario N1G 2W1, Canada \\ †Animal Welfare Program, University of British Columbia, Vancouver, British Columbia V6T 1Z4, Canada
}

\begin{abstract}
Surgical correction of left displaced abomasum (LDA) is common in lactating dairy cattle. Despite the growing acceptance that abdominal surgery is painful, few cows are administered analgesia following LDA surgery. The objective of this research was to examine the effect of administering a label dose of ketoprofen on physiological and behavioral indicators of pain in dairy cattle. Holstein cows were enrolled in a field study following LDA surgery. Surgery was performed using the standing right flank (RF) approach or the paramedian (PARA) approach. Using a triple-blind randomized trial, each animal was assigned to receive either $3 \mathrm{mg}$ of ketoprofen $/ \mathrm{kg}$ of body weight or saline (the equivalent volume) by intramuscular injection immediately following surgery and $24 \mathrm{~h}$ postoperatively. Physiological parameters (heart rate, respiration rate, and rumen motility), blood $\beta$-hydroxybutyrate (BHBA) levels, and an assessment of cow attitude were measured on the day of surgery, and at 2 follow-up visits (visit $1=3 \pm$ $0.9 \mathrm{~d}$ and visit $2=9 \pm 1.2 \mathrm{~d}$ postsurgery; $\mathrm{n}=175$ ). Milk production and culling were recorded for all cows enrolled in the study. Producers assessed their cows' attitudes and appetites daily for the first $3 \mathrm{~d}$ following surgery. A subset of cows $(\mathrm{n}=37)$ were fitted on the day of surgery with a 3 -axis accelerometer on the hind leg to assess lying behavior. Continuous and binary outcome data were analyzed using multivariable mixed linear and mixed logistic models, respectively, with cow modeled as a random effect. Ketoprofen did not alter the physiological measures, BHBA levels, or behavioral outcomes measured. Cows subjected to RF surgery had longer lying times [model coefficient $\beta=228.9 \mathrm{~min}$; 95\% confidence interval (CI): 122.2 to 335.6] in the first $3 \mathrm{~d}$ following surgery, and lower heart rates $(\beta=$ -9.4 beats $/ \mathrm{min}$; $95 \%$ CI: -12 to -6.9 beats $/ \mathrm{min}$ ) at the follow-up visits, compared with animals that under-
\end{abstract}

Received March 23, 2012.

Accepted November 20, 2012.

${ }^{1}$ Corresponding author: tduffiel@uoguelph.ca went PARA surgery. Regardless of surgical procedure, BHBA decreased from surgery day to visit $1(\beta=-1.9$ $\mathrm{mmol} / \mathrm{L} ; 95 \% \mathrm{CI}:-2.1$ to -1.7$)$ and visit $2(\beta=-2.0$ $\mathrm{mmol} / \mathrm{L} ; 95 \%$ CI: -0.2 .2 to -1.8$)$. Producer reports indicated that animals that received ketoprofen were more likely to begin eating when provided fresh feed during the first $3 \mathrm{~d}$ following surgery compared with those that received saline (odds ratio $=4.8 ; 95 \%$ CI: 0.97 to 23.8). These results indicate that PARA surgery may be more painful relative to lying down than the $\mathrm{RF}$ approach. The apparent differences in appetite or attitude in cows that received ketoprofen reported by producers warrant further investigation.

Key words: displaced abomasum surgery, pain, dairy cow, analgesia

\section{INTRODUCTION}

There is widespread and growing attention to animal welfare issues in food animal production (Hudson et al., 2008). Currently, little information exists on pain management following routine surgeries in dairy cows, likely due to the lack of understanding of means to measure pain in these animals. Surgical intervention for abomasal displacement is the most common surgery that occurs in adult dairy cows (Hewson et al., 2007). Given that the incidence risk of left displaced abomasum (LDA) has been reported to be between 3 and $7 \%$ of calvings (Gröhn, 2000; LeBlanc et al., 2002, Chapinal et al., 2011), it is estimated that over 30,000 of the 1 million dairy cows in Canada (Canadian Dairy Information Centre, 2011) will experience an LDA and undergo abdominal surgery each year. In a survey of Canadian veterinarians, the mean pain score for a displaced abomasum omentopexy was 7.2 out of 10 (Hewson et al., 2007). Respondents to a New Zealand survey gave a median pain score of 9 out of 10 for LDA surgery (Laven et al., 2009), and a British survey reported that a pain assessment for a laparotomy in cattle of 3 to 7 out of 10 (Watts and Clarke, 2000). Essentially all cows that underwent an omentopexy for displaced abomasum received analgesia, and the drugs most commonly 
administered were lidocaine and xylazine (Hewson et al. 2007). Watts and Clarke (2000) reported that 57\% of cases involved cows receiving a nonsteroidal antiinflammatory drug (NSAID; e.g., ketoprofen or flunixin meglumine) following laparotomy surgery. Few analgesics exist that are approved for use in lactating dairy cows in the United States and Canada, and many that are approved, or those for which prescribing data are available, require milk and meat withdrawal periods. Although some veterinary practitioners may include the use of NSAID as part of postoperative care, use of analgesics is limited in dairy cattle production (Hewson et al., 2007; Newman et al., 2008; Croney and Anthony, 2011).

Minimizing pain in companion animals has been an integral part veterinary practice (Hansen, 2003), and has long been recognized as a key component when evaluating animal welfare (Fraser et al., 1997). However, the assessment of pain in cattle has been challenging, as their stoic nature likely masks many of the common pain behaviors often used to assess pain in nonhuman animals (Dobromylskyj et al., 2000; Hudson et al., 2008; Weary et al., 2009). As a consequence of their stoic nature, the visible and more easily detectable clinical signs, such as lameness, may only occur with severe pain caused by the advanced progression of disease (O'Callaghan, 2002).

Although traditional postsurgical ancillary treatments of LDA include antibiotics, intravenous dextrose, and propylene glycol drench, few veterinarians include postoperative pain medications. Nonsteroidal antiinflammatory drugs have been successfully administered in rodents after surgery for pain relief and to reduce inflammation and prostaglandin synthesis (Pairet and Ruckebusch, 1989; De Winter et al., 1998). Nonsteroidal antiinflammatory drug therapy has also been shown to alleviate signs of visceral pain in cattle (Constable et al., 1997), and as a preoperative treatment to make an animal less likely to lie down during a standing laparotomy (Van Metre et al., 2005). Treated cows did sometimes lie down at the time of painful manipulation of viscera, indicating that the NSAID therapy was not adequate (Constable et al., 1997; Van Metre et al., 2005).

Ketoprofen (Anafen; Merial Canada Inc., Baie d'Urfé, QC, Canada) is approved in Canada, but not in the United States, for the symptomatic treatment of fever, pain, and inflammation associated with a variety of conditions in dairy and beef cattle. The conditions listed on the label include respiratory tract infections, mastitis, udder edema, downer cow syndrome, endotoxemia, simple gastrointestinal disorders, arthritis, and traumatic musculoskeletal injuries (Merial Canada Inc., 2002). The label claims for pain and inflamma- tion make it reasonable to study its effects following abdominal surgery. Furthermore, no milk withdrawal is associated with the administration of this drug. Therefore, ketoprofen was chosen to be studied in this trial.

Ketoprofen has also been used for managing postsurgical pain following dehorning. A single intramuscular injection of ketoprofen at the time of a cornual nerve block resulted in reduced serum cortisol in young calves dehorned with a butane dehorner (Milligan et al., 2004). A follow-up study of the same design, but in older calves dehorned with an electric cautery device, resulted in reductions in pain-related behavior (ear flicks) and improved feed intake (Duffield et al., 2010).

The type of surgical procedure used has also been shown to affect pain-related behaviors. For instance, Seeger et al. (2006) observed that cows that underwent LDA correction by laparoscopic abomasopexy had a more rapid return to presurgery feed intake levels and more rapid increase in milk yield compared with cows that underwent a standing right flank (RF) surgery. The laparoscopic technique was found to be less invasive and suggested to result in less postoperative pain based on the feed intake results, but no formal pain assessment was done. To date, no work has been published on postsurgical pain management following LDA surgery, or different approaches used in the field [e.g., RF vs. paramedian (PARA) approaches].

The objectives of this research were to assess the effects of ketoprofen on physiological, behavioral, and production parameters in dairy cattle following LDA surgery. The hypothesis was that the administration of ketoprofen would reduce pain in the hours following LDA surgery and so result in increased appetite and, in turn, reduced blood BHBA concentration and increased milk production compared with cows provided a placebo.

\section{MATERIALS AND METHODS}

The experiment began in May 2009 and ended in June 2010 and was conducted in association with 4 veterinary practices within $100 \mathrm{~km}$ of Guelph, Ontario, Canada (3 private clinics and 1 university field service). Holstein cattle $(n=198)$ from 118 farms that had been clinically diagnosed with LDA and that received surgical abomasopexy correction by a veterinarian were enrolled in this study. Table 1 summarizes the reasons and the number of animals per treatment group that were excluded from the statistical analysis. Of the animals included in the statistical analysis, there were 107 multiparous cows, with an average lactation number of $3.4( \pm 1.3 \mathrm{SD})$ and 42 primiparous cows. These animals underwent either a standing RF laparotomy $(\mathrm{n}=107)$ or a ventral PARA approach $(\mathrm{n}=68)$. The average 
Table 1. Summary of reasons for the number of animals excluded from analysis by treatment group

\begin{tabular}{|c|c|c|}
\hline Reason & $\begin{array}{l}\text { Number in the } \\
\text { ketoprofen group }\end{array}$ & $\begin{array}{l}\text { Number in the } \\
\text { saline group }\end{array}$ \\
\hline Total enrolled & 98 & 100 \\
\hline 1. Missing enrollment and (or) follow-up visit data from the veterinarian or study technician & 3 & 4 \\
\hline 3. Removed at producer's discretion to receive other treatment & 1 & 1 \\
\hline 4. Removed because animal was not a Holstein, but a Jersey & 0 & 1 \\
\hline 6. Animal did not receive the second treatment & 1 & 0 \\
\hline 7. Animal received surgery $>30$ DIM & 0 & 1 \\
\hline Total & 10 & 13 \\
\hline Number used in final analysis & 88 & 87 \\
\hline
\end{tabular}

surgery time following calving was $15 \mathrm{~d} \pm 1 \mathrm{~d}$ (mean $\pm \mathrm{SD})$. A xylazine sedative before surgery was given to $62 \%$ of the ketoprofen-treated animals and $52 \%$ of the saline-treated animals enrolled in this trial. All of the cows undergoing surgery received a local anesthetic of lidocaine as an inverted-L block (predominantly for PARA) or a proximal or distal paravertebral block (predominantly for RF). Efficacy of the block was determined by pricking the skin at the incision site with an 18-gauge needle and evaluating the response of the animal. If necessary, more lidocaine was administered locally before incision.

The type of surgery was largely dependent on which veterinary clinic enrolled the animal (2 private clinics performed only $\mathrm{RF}$; the third private clinic performed $100 \%$ PARA; the university field service performed $50 \% \mathrm{RF}$ and $50 \%$ PARA). All animals belonged to herds on milk recording with CanWest DHI (Guelph, ON, Canada). Each animal enrolled in this trial was allocated to 1 of 2 treatment groups in a triple-blind manner (i.e., people giving the injections, collecting the data, and the person performing the statistical analyses were unaware of treatment assignments; Schulz and Grimes, 2002) following surgery. The treatment group ( $\mathrm{n}=88$ cows) was randomly given ketoprofen (Anafen; Merial Canada Inc.) at the label dose of $3 \mathrm{mg} / \mathrm{kg}$ of BW by intramuscular injection at the time of surgery (d 0), before releasing the cow, followed by a second injection approximately $24 \mathrm{~h}$ later (d 1). The placebo group ( $\mathrm{n}=87$ cows) was given an equivalent volume of saline solution intramuscularly on $\mathrm{d} 0$ and approximately $24 \mathrm{~h}$ postsurgery (d 1). The BW was estimated by the veterinarian at time of surgery to determine the approximate dose to be given (between 20 and $25 \mathrm{~mL}$ of solution).

The participating veterinary practices were provided with packages that were randomly numbered, and were used in numerical order. Each package consisted of a vial of either ketoprofen or saline solution for 2 injections per cow (50 mL total), and an enrollment sheet for the veterinarian that was filled out at the time of surgery plus a follow-up questionnaire for the producer. Each veterinary practice was also provided with a hand-held glucometer (Precision Xtra; Abbott Laboratories Ltd., Saint-Laurent, QC, Canada) and ketone test strips for measuring BHBA concentration in blood (previously validated by Iwersen et al., 2009). The veterinarian or the study technician collected a blood sample at the time of surgery to measure BHBA concentration, administered the first injection, and then recorded and sent the data to the trial manager. Producers administered the second dose of the experimental treatment approximately $24 \mathrm{~h}$ after surgery. The producer or primary caregiver of the cow recorded qualitative data on each cow's attitude and appetite for $3 \mathrm{~d}$ after surgery. A simple ethogram, described in the behavioral assessment section below, was used by the veterinarian or study technicians to assess the animal's demeanor and pain level at the time of enrollment (surgery day) and in the days following surgery. The study technician visited the farm twice: between 2 and $4 \mathrm{~d}$ (visit 1) and again between 8 and $10 \mathrm{~d}$ (visit 2) after surgery to collect follow-up observational data [behavioral assessment, physical examination (see description below)], and blood samples to measure BHBA concentration, also used to detect ketosis (based on the cut-off of $\geq 1.4$ mmol/L; Geishauser et al., 2001).

All cows enrolled in the study were provided 300 to $500 \mathrm{~mL}$ of propylene glycol/d for $3 \mathrm{~d}$ after surgery. Veterinarians and producers were requested to document all other treatments given to the cow (e.g., dextrose, minerals or vitamins, and antibiotics) throughout the course of the surgical follow-up (10 d).

\section{Physical Examination}

Prior to surgery the veterinarian or the study technician gave all cows a basic routine physical examination, 
and this was repeated by the study technician at visits 1 and 2. This physical examination consisted of measuring respiration rate, heart rate, rumen motility [number of contractions in $1 \mathrm{~min}$ and contraction strength $(0=$ none, $1=$ poor, $2=$ moderate, and $3=$ strong)], and rectal temperature. Assessment of the incision site was done by the study technician at each postsurgical visit and a photograph was taken for reference purposes. Visual assessment consisted of the following scores: $1=$ no abnormalities noted (healing well); 2 = swelling and redness at suture site, $3=$ swelling with infection (pus present) at suture site, $4=$ dehiscence of the incision, and $5=$ comment from the study technician if appearance differed from 1 to 4 and was abnormal.

\section{Behavioral Assessment}

A simple ethogram was developed using a modified Delphi technique (Linstone and Turoff, 1975) and applied to the cow immediately before surgery by the veterinarian, and by the study technician at visit 1 and visit 2 . The ethogram included the following characteristics and descriptors to assess the animal's demeanor on the day of surgery: $\mathbf{B A R}=$ bright, alert, and responsive; $\mathbf{Q A R}=$ quiet, alert, and responsive; $\mathrm{D}=$ dull/depressed; NR = nonresponsive. The producer was also requested to undertake an assessment for whether the cow was BAR or QAR daily for $3 \mathrm{~d}$ postsurgery.

A subset of cows $(\mathrm{n}=37$; randomly chosen from all veterinary clinics) were fitted with a 3 -axis accelerometer (Hobo Pendant G loggers; Hoskin Scientific Ltd., Burnaby, BC, Canada) on the right hind leg on the day of surgery to access the lying behavior of the cow at $1 \mathrm{~min} /$ interval (validated by Ledgerwood et al., 2010). The surgical procedure and housing for these animals were 9 freestall PARA, 7 tiestall PARA, 14 freestall RF, 7 tiestall RF, and 1 unknown housing RF. The device was removed at visit 2 by the study technician. The data from the loggers were downloaded onto a computer and analyzed.

\section{Milk Production and Culling}

Dairy herd improvement milk production and milk components were used to assess response to treatment. The first 2 tests following the LDA surgery were used for this purpose. In addition, culling data (up to $200 \mathrm{~d}$ following surgery) for the lactation were also collected for 149 of the total animals enrolled in the study.

\section{Statistical Analysis}

All descriptive statistics, model building, and analyses were performed using STATA Intercooled 10.1 software (StataCorp LP, College Station, TX). Mixed multivariable models were built using a random intercept to account for multiple measurements being taken from each cow. Mixed linear models were performed for the outcomes of heart rate, respiration rate, rumen motility, BHBA concentration, daily lying time, and milk production using the following independent variables: treatment, time, surgical procedure, and parity ( 1 and $\geq 2$; for the respiration rate and milk production models only). Mixed logistic regression models were used for the binary outcomes of incision appearance, attitude assessment by the veterinarian or study technician, attitude assessment by the producer, and appetite assessment by the producer, using the following independent variables: treatment, time, surgical procedure, and parity number (for the producer's attitude and appetite assessment of the cow). A logistic regression analysis for the odds of an animal being culled was conducted, with treatment, surgical procedure, and parity as independent variables. All tests were 2 sided and significance was based on $\alpha \leq 0.05$. For all models, univariable models were screened and variables were kept in the final model if they were significant at the $\alpha$ $<0.05$ level, acted as a confounder, or were part of a significant interaction term. A confounder variable was a nonintervening variable that made a $20 \%$ or greater change in the coefficient of significant variables in the final model (Dohoo et al., 2003). Interactions between treatment and any significant covariates in the final model were tested. Linearity was assessed using a locally weighted scatterplot smoothing (LOWESS) curve for continuous variables (note: no transformations of the data were required).

To identify outliers, we examined standardized residuals at the observation level for the mixed linear regression models, and Pearson and deviance residuals were examined for both the logistic and mixed logistic regression models. Best linear unbiased predictors were also examined for outliers in all random effects models. Normality and homogeneity of variance were assessed for the observation-level standardized residuals for mixed linear models and for the cow-level BLUP of all mixed models. A Pearson goodness-of-fit test was performed for the culling model using logistic regression. Predicted values for heart rate, respiration rate, rumen motility, and daily lying time were estimated while fixing all the independent variables to their referent categories.

\section{RESULTS}

\section{Physical Examination and Blood Parameters}

For follow-up visit 1, 22 and $28 \%$ of cows were at $2 \mathrm{~d}$ after surgery, 31 and $36 \%$ at $3 \mathrm{~d}$, and 38 and $34 \%$ at $4 \mathrm{~d}$ 
in the ketoprofen and control groups, respectively. The remainder in each group were sampled outside of the predefined visit time (d 2-4) by 1 or $2 \mathrm{~d}$ but retained in the analysis for this visit time. Final regression models for the physical examination components for day of surgery, as well as both follow-up visits (mean \pm SD: visit $1=3 \pm 0.9 \mathrm{~d}$ and visit $2=9 \pm 1.2 \mathrm{~d}$ postsurgery) are summarized in Table 2. The physical examination parameters were not significantly different between treatment groups. Furthermore, the heart rates of the cows that underwent an RF correction (mean \pm SD: heart rate $=73.5 \pm 20.7$ beats $/ \mathrm{min}$ ) were significantly lower than the heart rates of those that underwent a PARA surgical procedure (mean $\pm \mathrm{SD}$ : heart rate $=83.2 \pm$ 19.2 beats/min; Table 2 ). The rumen contraction rate per minute significantly increased over time and was significantly lower for the RF procedure compared with the PARA surgical procedure [contractions/min (mean $\pm \mathrm{SD}$ ): surgery d, RF $=0.88 \pm 0.83$; surgery d, PARA $=1.2 \pm 0.67$; visit $1, \mathrm{RF}=1.0 \pm 0.72$; visit 1 , PARA $=1.5 \pm 0.99$; visit $2, \mathrm{RF}=1.1 \pm 0.72$; visit 2 , PARA $=1.7 \pm 0.95$; Table 2]. Rectal temperatures were not significantly different between treatments, surgical techniques, or time period and averaged $38.5 \pm 0.59$ (mean $\pm \mathrm{SD}$ ) across all cows.

The blood BHBA levels were not different between treatment groups for the study period, but the BHBA levels were significantly lower on the follow-up visits compared with the day of surgery (Table 3 ). The concentration of BHBA (accounting for treatment, time, and surgical procedure) was $2.9 \mu \mathrm{mol} / \mathrm{L}$ (95\% CI: 2.6 to 3.2$)$ on the day of surgery, $1.0 \mu \mathrm{mol} / \mathrm{L}(95 \% \mathrm{CI}: 0.8$ to 1.22$)$ at visit 1 , and $0.9 \mu \mathrm{mol} / \mathrm{L}(95 \%$ CI: 0.7 to 1.1$)$ at visit 2 . The proportion of cows that were ketotic at the time of surgery was $71 \%, 16 \%$ at visit 1 , and $12 \%$ at visit 2 .

The odds of the incision sites being abnormal (swollen and red), based on visual assessment, for the ketoprofen and the placebo groups were not significantly different after controlling for treatment, surgical procedure, and time [odds ratio $(\mathrm{OR})=2.0 ; 95 \%$ CI: 0.66 to $6.2 ; P=$ 0.22 ). Significantly lower odds of swelling and redness existed for the RF surgical technique $(9.8 \%$ of incision sites were abnormal) compared with the PARA procedure $(19.9 \%$ of incision sites were abnormal; OR $=$ $0.24 ; 95 \%$ CI: 0.07 to $0.80 ; P=0.02)$.

\section{Behavioral Assessment}

The odds of being BAR assessed by the veterinarian or study technician were significantly greater at the second follow-up visit ( $88.6 \%$ of cows were BAR) than the day of surgery $(74.4 \%$ of cows were BAR; OR = 3.2; $95 \%$ CI: 1.7 to $6.1 ; P=0.001)$, but no significant treatment effect was observed $(\mathrm{OR}=1.5 ; 95 \%$ CI: 0.8 to $2.6 ; P=0.17)$. No difference existed between treatment groups in the odds of being assessed BAR by the producer (Table 4). The odds of being BAR on $d 3$ (71.3\% of cows BAR) following surgery compared with d 1 following surgery ( $60.3 \%$ of cows BAR) was significantly greater, and animals that underwent RF surgery had significantly lower odds of being BAR compared with animals that underwent PARA surgery (Table 4). The odds of being BAR significantly increased with lactation number (Table 4).

In the appetite assessment model, there was a tendency for the odds of eating at fresh feed delivery for animals in the ketoprofen group (83\% of animals came up to eat right away at fresh feed delivery) to be greater compared with the animals in the saline group ( $75 \%$ of animals came up to eat right away at fresh feed delivery; $P=0.05$; Table 4 ). It should be noted that lactation number acted as a confounder in this model (Table 4).

The final mixed linear regression model for total daily lying time for the $3 \mathrm{~d}$ following surgery is summarized in Table 5. We observed no differences in total daily lying time between cows treated with or without ketoprofen. However, animals that underwent RF surgery lay down significantly more per day over the first $3 \mathrm{~d}$ compared with the animals with PARA surgery (Table 5). Lying time over the first $3 \mathrm{~d}$ postsurgery for the animals that underwent RF surgery was $11.6 \mathrm{~h} / \mathrm{d}(95 \%$ CI: 9.8 to 13.3 ), and for animals that underwent PARA surgery was $7.74 \mathrm{~h} / \mathrm{d}$ (95\% CI: 6.1 to 9.4$)$. The number of lying bouts per day was $11.3( \pm 4.2 \mathrm{SD})$ in cows that had RF surgery and $9.1( \pm 3.9 \mathrm{SD})$ in those that had PARA surgery $(P=00.09)$.

\section{Production and Culling}

No differences existed between treatment groups or surgical procedures in milk production for the first and second DHI tests following surgery (mean \pm SD: first DHI test $=31.3 \pm 10.6 \mathrm{~kg}$; second DHI test $=37.97$ $\pm 11.3 \mathrm{~kg}$; model coefficient $\beta=1.8 ; 95 \% \mathrm{CI}:-1.6$ to $5.2 ; P=0.30)$. With respect to the odds of being culled during the study period, no differences existed between treatment groups or surgical procedures $(25.7 \%$ of animals were culled within 200 DIM), but animals that ate at fresh feed delivery on $\mathrm{d} 1$ had significantly lower odds of being culled after controlling for treatment, procedure, parity, and eating behavior $(\mathrm{OR}=0.33$; 95\% CI: 0.12 to $0.91 ; P=0.03)$.

We did not identify any outliers in the residual analyses. Based on the examination of observation-level residuals and BLUP in the mixed models, model fit was adequate. In the logistic regression model for cull- 
Table 2. Mixed linear regression models (with model coefficient $\beta, P$-value, and $95 \% \mathrm{CI}$ ) for each of the physical examination outcomes for 175 Holstein cows with left displaced abomasum (LDA) randomly assigned to receive ketoprofen $(3 \mathrm{mg} / \mathrm{kg}$ of BW) or saline (at an equivalent volume) by intramuscular injection at time of surgery and $24 \mathrm{~h}$ later

\begin{tabular}{|c|c|c|c|c|c|c|c|c|c|c|c|c|}
\hline \multirow[b]{2}{*}{ Item } & \multicolumn{3}{|c|}{ Heart rate (beats/min) } & \multicolumn{3}{|c|}{ Respiration rate (breaths/min) } & \multicolumn{3}{|c|}{ Rumen motility (contractions/min) } & \multicolumn{3}{|c|}{ Contraction strength $\left(\right.$ score $\left.^{1}\right)$} \\
\hline & $\beta$ & $P$-value & $95 \% \mathrm{CI}$ & $\beta$ & $P$-value & $95 \% \mathrm{CI}$ & $\beta$ & $P$-value & $95 \% \mathrm{CI}$ & $\beta$ & $P$-value & $95 \% \mathrm{CI}$ \\
\hline \multicolumn{13}{|l|}{ Variable } \\
\hline \multicolumn{13}{|l|}{ Treatment } \\
\hline Ketoprofen & 0.26 & 0.84 & -2.2 to 2.7 & -0.35 & 0.72 & -2.2 to 1.5 & 0.10 & 0.09 & -0.02 to 0.22 & 0.001 & 0.99 & -0.14 to 0.14 \\
\hline Saline & $\operatorname{Ref}^{2}$ & & & Ref & & & Ref & 0.08 & -0.02000 .22 & Ref & 0.05 & 0.17000 .17 \\
\hline \multicolumn{13}{|l|}{ Time $^{3}$} \\
\hline Visit 1 & 2.6 & 0.04 & 0.09 to 5.1 & 3.7 & $<0.001$ & 2.1 to 5.4 & 0.21 & $<0.001$ & 0.10 to 0.31 & 0.47 & $<0.001$ & 0.33 to 0.62 \\
\hline Visit 2 & 3.9 & 0.01 & 1.4 to 6.4 & 5.0 & $<0.001$ & 3.3 to 6.6 & 0.33 & $<0.001$ & 0.23 to 0.44 & 0.76 & $<0.001$ & 0.61 to 0.90 \\
\hline \multirow{2}{*}{\multicolumn{13}{|c|}{$\begin{array}{l}\text { Visit } 0 \\
\text { Procedure }^{4}\end{array}$}} \\
\hline & & & & & & & & & & & & \\
\hline $\mathrm{RF}$ & -9.4 & $<0.001$ & -12.0 to -6.9 & -0.44 & 0.65 & -2.3 to 1.5 & -0.41 & $<0.001$ & -0.53 to -0.29 & 0.01 & 0.9 & -0.13 to 0.15 \\
\hline PARA & Ref & & & Ref & & & Ref & & & Ref & & \\
\hline Lactation & - & - & - & -0.75 & 0.02 & -1.4 to -0.12 & - & - & - & - & - & - \\
\hline Intercept & 80.8 & - & 78.0 to 83.5 & 27.8 & - & 25.2 to 30.4 & 1.2 & - & 1.1 to 1.31 & 1.6 & - & 1.5 to 1.8 \\
\hline Random intercept & $\operatorname{Var}^{5}$ & $\mathrm{SE}$ & & Var & $\mathrm{SE}$ & & Var & $\mathrm{SE}$ & & Var & $\mathrm{SE}$ & \\
\hline Cow level & 22.7 & 0.88 & & 15.1 & 0.54 & & 0.07 & 0.03 & & 0.06 & 0.05 & \\
\hline Observation level & 139.8 & 0.45 & & 53.0 & 0.30 & & 0.24 & 0.02 & & 0.43 & 0.03 & \\
\hline
\end{tabular}

${ }^{1}$ Contraction strength score: $0=$ none; 1 = poor; 2 = moderate; $3=$ strong.

${ }^{2}$ Ref $=$ reference.

${ }^{3}$ Visit $0=$ surgery day; visit $1=2$ to $4 \mathrm{~d}$ postsurgery; visit $2=8$ to $10 \mathrm{~d}$ postsurgery.

${ }^{4} \mathrm{RF}=$ right flank procedure; PARA $=$ ventral paramedian procedure

${ }^{5}$ Var $=$ variance 
Table 3. Mixed linear regression model (with model coefficient $\beta, P$-value, and 95\% CI )for the blood BHBA concentration in 175 cows with left displaced abomasum (LDA) randomly assigned to receive ketoprofen (3 $\mathrm{mg} / \mathrm{kg}$ of BW) by intramuscular injection at surgery and $24 \mathrm{~h}$ later, or to a negative control

\begin{tabular}{|c|c|c|c|}
\hline \multirow[b]{2}{*}{ Item } & \multicolumn{3}{|c|}{ BHBA level } \\
\hline & $\beta$ & $P$-value & $95 \% \mathrm{CI}$ \\
\hline \multicolumn{4}{|l|}{ Variable } \\
\hline \multicolumn{4}{|l|}{ Treatment } \\
\hline Ketoprofen & -0.07 & 0.61 & -0.33 to 0.19 \\
\hline Saline & $\operatorname{Ref}^{1}$ & & \\
\hline \multicolumn{4}{|l|}{$\mathrm{Time}^{2}$} \\
\hline Visit 1 & -1.9 & $<0.001$ & -2.1 to -1.7 \\
\hline Visit 2 & -2.0 & $<0.001$ & -2.2 to -1.8 \\
\hline Surgery day & Ref & & \\
\hline \multicolumn{4}{|l|}{ Procedure $^{3}$} \\
\hline $\mathrm{RF}$ & -0.23 & 0.1 & -0.49 to 0.04 \\
\hline PARA & Ref & & \\
\hline Intercept & 2.9 & - & 2.6 to 3.2 \\
\hline Random intercept & Variance & $\mathrm{SE}$ & \\
\hline Cow level & 0.45 & 0.06 & \\
\hline Observation level & 0.93 & 0.04 & \\
\hline
\end{tabular}

ing, the Pearson goodness-of-fit test indicated that the model fit the data (chi-squared $=8.1 ; P=0.71$ ).

\section{DISCUSSION}

Ketoprofen is currently 1 of only 2 NSAID approved in Canada for lactating dairy cows, and has a label claim for pain in dairy cattle with no milk withdrawal period (Merial Canada Inc., 2002; Compendium of
Veterinary Products, 2011). Ketoprofen is, therefore, an analgesic option for veterinarians who choose to administer one to lactating dairy cattle following LDA surgery. However, this is the first study to investigate the effects of ketoprofen as a postoperative drug in the days following LDA surgery.

Collectively the results from this study indicate that ketoprofen did not significantly improve the quantitative measures included in this study. However,

Table 4. Mixed logistic regression model for the attitude and appetite assessment recorded by the producer for the first $3 \mathrm{~d}$ following surgery, by treatment and lactation, for 175 Holstein cows with left displaced abomasum (LDA) randomly assigned to receive ketoprofen $(3 \mathrm{mg} / \mathrm{kg}$ of $\mathrm{BW})$ or saline (at an equivalent volume) by intramuscular injection at time of surgery and $24 \mathrm{~h}$ later

\begin{tabular}{|c|c|c|c|c|c|c|}
\hline \multirow[b]{2}{*}{ Item } & \multicolumn{3}{|c|}{ Attitude assessment ${ }^{1}$} & \multicolumn{3}{|c|}{ Appetite assessment ${ }^{2}$} \\
\hline & OR & $P$-value & $95 \%$ CI & OR & $P$-value & $95 \%$ CI \\
\hline \multicolumn{7}{|l|}{ Variable } \\
\hline \multicolumn{7}{|l|}{ Treatment } \\
\hline Ketoprofen & 1.9 & 0.16 & 0.78 to 4.5 & 4.8 & 0.054 & 0.97 to 23.8 \\
\hline Saline & $\operatorname{Ref}^{3}$ & & & Ref & & \\
\hline \multicolumn{7}{|l|}{ Time } \\
\hline d 2 & 1.7 & 0.11 & 0.89 to 3.1 & 1.2 & 0.70 & 0.50 to 2.8 \\
\hline d 3 & 1.9 & 0.04 & 1.0 to 3.7 & 1.5 & 0.36 & 0.62 to 3.6 \\
\hline d 1 & Ref & & & Ref & & \\
\hline \multicolumn{7}{|l|}{ Procedure $^{4}$} \\
\hline RF surgery & 0.35 & 0.02 & 0.14 to 0.85 & 0.4 & 0.22 & 0.10 to 1.7 \\
\hline PARA surgery & Ref & & & Ref & & \\
\hline Lactation number & 1.4 & 0.04 & 1.0 to 1.9 & 1.1 & 0.64 & 0.67 to 1.9 \\
\hline Random intercept & Variance & SE & & Variance & $\mathrm{SE}$ & \\
\hline Cow level & 3.8 & 0.32 & & 7.1 & 0.26 & \\
\hline
\end{tabular}

${ }^{1}$ Producer recorded whether the cow was bright, alert, and responsive, or was quiet. OR = odds ratio.

${ }^{2}$ Producer recorded whether the cow ate at fresh feed delivery or not.

${ }^{3}$ Ref $=$ reference

${ }^{4} \mathrm{RF}=$ right flank surgical procedure; PARA $=$ ventral paramedian surgical procedure. 
Table 5. Mixed linear regression model (with model coefficient $\beta, P$-value, and $95 \% \mathrm{CI}$ ) for the daily lying time recorded by a 3-axis accelerometer (Hobo data logger; Hoskin Scientific Ltd., Burnaby, BC, Canada) for the first $3 \mathrm{~d}$ following left displaced abomasum (LDA) surgery by treatment and surgical procedure, for a subset of 37 cows with LDA randomly assigned to receive ketoprofen ( $3 \mathrm{mg} / \mathrm{kg}$ of BW) or saline (at an equivalent volume) by intramuscular injection at time of surgery and $24 \mathrm{~h}$ later

\begin{tabular}{|c|c|c|c|}
\hline \multirow[b]{2}{*}{ Item } & \multicolumn{3}{|c|}{ Daily lying time (min) } \\
\hline & $\beta$ & $P$-value & $95 \% \mathrm{CI}$ \\
\hline \multicolumn{4}{|l|}{ Variable } \\
\hline \multicolumn{4}{|l|}{ Treatment } \\
\hline Ketoprofen & -45.2 & 0.40 & -151.2 to 60.9 \\
\hline Saline & $\operatorname{Ref}^{1}$ & & \\
\hline \multicolumn{4}{|l|}{ Time } \\
\hline d 2 & -9.3 & 0.73 & -62.2 to 43.6 \\
\hline d 3 & -19.2 & 0.48 & -72.6 to 34.2 \\
\hline d 1 & Ref & & \\
\hline \multicolumn{4}{|l|}{ Procedure ${ }^{2}$} \\
\hline RF surgery & 228.9 & $<0.001$ & 122.2 to 335.6 \\
\hline PARA surgery & Ref & & \\
\hline Intercept & 464.6 & - & 367.1 to 562.2 \\
\hline Random intercept & Variance & SE & \\
\hline Cow level & $22,310.4$ & 21.9 & \\
\hline Observation level & $13,473.6$ & 9.7 & \\
\hline
\end{tabular}

the qualitative assessment by the producer, who was blinded to treatment, indicated that ketoprofen injections increased the odds of the animal eating at fresh feed delivery over the first $3 \mathrm{~d}$ postsurgery compared with cows that received saline. It should be noted that the $P$-value was close to the significant cut-off of 0.05 . Consequently, the improvement shown by the larger odds of eating at fresh feed delivery is worth investigating further.

The failure to note any differences between treatment groups in the respiration rate, heart rate, and the BHBA levels could be explained by the fact that the plasma half-life of ketoprofen is $2 \mathrm{~h}$, and $80 \%$ of the dose is eliminated in the urine within $24 \mathrm{~h}$ of administration (Merial Canada Inc., 2002). We did not find differences in rumen contraction and strength between the treated and untreated animals. Wittek et al. (2008) observed an improvement in rumen contraction rate on the day following abomasal correction surgery in animals that received flunixin meglumine compared with the control group. In the present field study, the first visit was scheduled for 2 to $4 \mathrm{~d}$ following the surgery to accommodate the study technicians' schedules. Because no differences existed between d 2, 3, and 4 for any of the outcomes, they were modeled as 1 category: visit 1 . Those cows visited on d 2 may have still had circulating levels of ketoprofen but there were too few cow visits (16 in the ketoprofen group and 21 in the placebo group) on d 2 in each treatment group to detect differences between treatment groups. We encourage future research to include a controlled trial where animals are observed during the time period when ketoprofen is known to be active. Also, further research is warranted to evaluate the heart and respiration rates in the hours around surgery as potential postoperative pain indicators.

Assessment of the cows' attitudes would have been strengthened by formal assessment of agreement among observers, but each veterinarian and producer only assessed a few cows. Although the attitude assessments completed by the veterinarians and the study technicians did not identify any treatment effects, a tendency existed in the producer's observations that animals that received ketoprofen were more likely to eat immediately when fresh feed was delivered for the first time each day over the first $3 \mathrm{~d}$ compared with the animals in the saline group. It is noteworthy that the producer was blinded to treatment. This apparent improvement in feeding behavior could result in an increase in DMI. Therefore, we suggest a follow-up study that monitors individual feed intake over the first few days after surgery to verify this observation, as improving DMI postsurgery would likely be important to recovery from surgery. Interestingly, the animals that were culled within the first 200 DIM also had decreased odds of eating at the time of fresh feed delivery, a time when cows are known to be highly motivated to access the feed bunk (DeVries et al., 2005). Given that the cows were operated on approximately 2 wk postpartum, it could be speculated that those cows that received the ketoprofen were more likely to consume feed and, thus, were able to better mitigate the negative effects of pro- 
longed negative energy balance compared with those cows that only received saline. We encourage further research to test this hypothesis.

The failure to detect differences in milk production and culling between the ketoprofen- and saline-treated animals may be due to the timing of the ketoprofen administration and short duration of effect compared with these measures, which were taken well after the drug was cleared from the animal. The milk data were from DHI milk tests (i.e., whole-herd testing at approximately 5 -wk intervals during the year), and not from daily milk weights. Although we had hoped to collect daily milk weight for the first $10 \mathrm{~d}$ following surgery, the majority of farms in the area $(>85 \%$; D. Kelton, University of Guelph, Guelph, ON, Canada, personal communication) do not have daily milk weights. Furthermore, because we could not predict where LDA surgery would occur, we only had 19 cows with daily milk weight data, which was insufficient for analysis. We suggest that future work in this area monitor daily milk weight collection following surgery, as this would provide a more direct measure of the effects of surgery and postoperative pain management on production.

The decreased blood BHBA levels observed on both of the follow-up visits compared with the levels recorded on the surgical day, the latter levels being above the elevated predicted level of BHBA ketosis based on the cut-off of $1.4 \mathrm{mmol} / \mathrm{L}$ reported by Geishauser et al. (2001), suggest that the surgical correction itself was effective at improving BHBA levels and, thus, returning the animal to a more normal production. It is noteworthy that the oral propylene glycol after surgery may have helped in the resolution of hyperketonemia, as suggested by the decrease in milk ketones following propylene glycol treatment in cows that were borderline ketotic (Emery et al., 1964).

The surgical approach was not randomly assigned but was a function of the preferred technique of the attending veterinarian. It is unclear why the initial heart rates differed between the surgical techniques but both groups were within normal limits (60 to 80 beats/min). Apparent associations with surgical technique might be confounded by other animal or clinician variables. Animals that underwent RF surgery compared with animals that underwent a PARA surgical correction had a lower heart rate and a lower rumen contraction rate. Animals that underwent RF surgery lay down for approximately $11 \mathrm{~h}$, which was $30 \%$ longer lying than animals that underwent PARA surgery. The average lying time for transition cows has been reported to be approximately 10 (Huzzey et al., 2005) and 12 h/d (Dechamps et al., 1989), for freestall- and tiestall-housed animals, respectively. Interestingly, farmers assessed a cow's attitude as more likely to be QAR than BAR, regardless of whether she was lying or standing, for animals that underwent RF surgery. Perhaps this could be explained by the fact that cows were lying down more, as opposed to standing longer, as in the paramedian group. The short lying time compared with normal lying times for cattle in the PARA surgical group may be an indication of reluctance to lie down due to pain from the incision site. The shorter lying time in the PARA correction group could be useful as an assessment of pain following abdominal surgery in cows in future studies.

\section{CONCLUSIONS}

This study did not find differences in physiologic measures, lying time, ketosis, milk production in early lactation, or culling, between ketoprofen and placebo groups. As used and measured in this study, ketoprofen administered following postsurgery did not appear to have benefits for pain management. However, cows that were administered ketoprofen did show increased odds of eating at fresh feed delivery, which could indicate some benefit, and further research is recommended. Future research should investigate shorter-term changes in physiological and behavioral parameters in combination with more frequent and (or) longer duration of administration of ketoprofen or with different analgesics with longer half-lives. The increased heart rate and respiration rates at the follow-up visits could suggest postsurgical pain in these animals. Furthermore, the decreased lying time observed in the animals that underwent a PARA procedure provides evidence of reluctance to lie on the incision site and, thus, a potential need for postoperative pain management in these animals.

\section{ACKNOWLEDGMENTS}

The authors thank the managers of the participating herds, the veterinary clinics, and the University of Guelph Ontario Veterinary College Ruminant Field Service, as well as all of the help from the summer students. Funding for this research was generously provided by Merial Canada Ltd. (Baie d'Urfé, QC, Canada) and an Ontario Ministry of Agriculture, Food and Rural Affairs (Guelph, ON, Canada) grant to T. F. Duffield.

\section{REFERENCES}

Canadian Dairy Information Centre. 2011. Number of dairy cows by province. Accessed June 15, 2011. http://www.dairyinfo.gc.ca/ pdf/dairy_cows_by_prov.pdf.

Chapinal, N., M. Carson, T. F. Duffield, M. Capel, S. Godden, M. Overton, J. E. P. Santos, and S. J. LeBlanc. 2011. The association of serum metabolites with clinical disease during the transition period. J. Dairy Sci. 94:4897-4903. 
Compendium of Veterinary Products. 2011. Product CategoryDairy Cattle: Nonsteroidal drug (NSAID). Accessed Nov. 20, 2011. http://cca.naccvp.com/index.php?m=catindex _ list\&id $=1038 \&$ spcsId $=1530$.

Constable, P. D., G. St Jean, B. L. Hull, D. M. Rings, D. E. Morin, and D. R. Nelson. 1997. Intussusception in cattle: 336 cases (19641993). J. Am. Vet. Med. Assoc. 210:531-536.

Croney, C. C., and R. Anthony. 2011. Invited review: Ruminating conscientiously: Scientific and socio-ethical challenges for US dairy production. J. Dairy Sci. 94:539-546.

De Winter, B. Y., G. E. Boeckxstaens, J. G. De Man, T. G. Moreels, A. G. Herman, and P. A. Pelckmans. 1998. Differential effect of indomethacin and ketorolac on postoperative ileus in rats. Eur. J. Pharmacol. 344:71-76.

Dechamps, P., B. Nicks, B. Canart, M. Gielen, and L. Istasse. 1989. A note on resting behaviour of cows before and after calving in two different housing systems. Appl. Anim. Behav. Sci. 23:99-105.

DeVries, T. J., M. A. G. von Keyserlingk, and K. A. Beauchemin 2005. Frequency of feed delivery affects the behavior of lactating dairy cows. J. Dairy Sci. 88:3553-3562.

Dobromylskyj, P., P. A. Flecknell, B. D. Lascelles, A. Livingston, P. Taylor, and A. Waterman-Pearson. 2000. Pain assessment. Page 53-76 in Pain Management in Animals. P. Flecknell and A. Waterman-Pearson, ed. WB Saunders, London, UK.

Dohoo, I., W. Martin, and H. Stryhn. 2003. Confounder bias: Analytic control and matching. Pages 235-272 in Veterinary Epidemiologic Research. S. M. McPike, ed. Atlantic Veterinary College (AVC) Inc., Charlottetown, PEI, Canada.

Duffield, T. F., A. Heinrich, S. T. Millman, A. DeHaan, S. James, and K. Lissemore. 2010. Reduction in pain response by combined use of local lidocaine anesthesia and systemic ketoprofen in dairy calves dehorned by heat cauterization. Can. Vet. J. 51:283-288.

Emery, R. S., N. Burg, L. D. Brown, and G. N. Blank. 1964. Detection, occurrence, and prophylactic treatment of borderline ketosis with propylene glycol feeding. J. Dairy Sci. 47:1074-1079.

Fraser, D., D. M. Weary, E. A. Pajor, and B. N. Milligan. 1997. A scientific conception of animal welfare that reflects ethical concerns. Anim. Welf. 6:187-205.

Geishauser, T., K. Leslie, D. Kelton, and T. Duffield. 2001. Monitoring for subclinical ketosis in dairy herds. Compend. Contin. Educ. Pract. Vet. 23:S65-S71.

Gröhn, Y. T. 2000. Milk yield and disease: Towards optimizing dairy herd health and management decisions. Bovine Pract. 34:32-40.

Hansen, B. D. 2003. Assessment of pain in dogs: Veterinary clinical studies. ILAR J. 44:197-205.

Hewson, C. J., I. R. Dohoo, K. A. Lemke, and H. W. Barkema. 2007. Canadian veterinarians' use of analgesics in cattle, pigs, and horses in 2004 and 2005. Can. Vet. J. 48:155-164.

Hudson, C., H. Whay, and J. Huxley. 2008. Recognition and management of pain in cattle. In Practice 30:126-134.

Huzzey, J. M., M. A. G. Von Keyserlingk, and D. M. Weary. 2005. Changes in feeding, drinking, and standing behavior of dairy cows during the transition period. J. Dairy Sci. 88:2454-2461.
Iwersen, M., U. Falkenberg, R. Voigtsberger, D. Forderung, and W Heuwieser. 2009. Evaluation of an electronic cowside test to detect subclinical ketosis in dairy cows. J. Dairy Sci. 92:2618-2624.

Laven, R. A., J. N. Huxley, H. R. Whay, and K. J. Stafford. 2009. Results of a survey of attitudes of dairy veterinarians in New Zealand regarding painful procedures and conditions in cattle. N. Z. Vet. J. $57: 215-220$.

LeBlanc, S. J., T. F. Duffield, K. E. Leslie, K. G. Bateman, J. TenHag, J. S. Walton, and W. H. Johnson. 2002. The effect of prepartum injection of vitamin $\mathrm{E}$ on health in transition dairy cows. J. Dairy Sci. 85:1416-1426.

Ledgerwood, D. N., C. Winkler, and C. B. Tucker. 2010. Evaluation of data loggers, sampling intervals, and editing techniques for measuring the lying behavior of dairy cattle. J. Dairy Sci. 93:5129-5139.

Linstone, H. A., and M. Turoff. 1975. The Delphi method: Techniques and Applications. Addison-Wesley Publishing Co., Boston, MA

Merial Canada Inc. 2002. Anafen Injection (large animal). In Compendium of Veterinary Products, CD ed. A. Arrioja-Dechert, ed. North American Compendiums Inc., Port Huron, MI.

Milligan, B. N., T. Duffield, and K. Lissemore. 2004. The utility of ketoprofen for alleviating pain following dehorning in young dairy calves. Can. Vet. J. 45:140-143.

Newman, K. D., D. Harvey, and J.-P. Roy. 2008. Minimally invasive field abomasopexy techniques for correction and fixation of left displacement of the abomasum in dairy cows. Vet. Clin. North Am. Food Anim. Pract. 24:359-382.

O'Callaghan, K. 2002. Lameness and associated pain in cattle-Challenging traditional perceptions. In Practice 24:212-219.

Pairet, M., and Y. Ruckebusch. 1989. On the relevance of non-steroidal anti-inflammatory drugs in the prevention of paralytic ileus in rodents. J. Pharm. Pharmacol. 41:757-761.

Schulz, K. F., and D. A. Grimes. 2002. Blinding in randomised trials: Hiding who got what. Lancet 359:696-700.

Seeger, T., H. Kümper, K. Failing, and K. Doll. 2006. Comparison of laparoscopic-guided abomasopexy versus omentopexy via right flank laparotomy for the treatment of left abomasal displacement in dairy cows. Am. J. Vet. Res. 67:472-478.

Van Metre, D. C., R. J. Callan, T. N. Holt, and F. B. Garry. 2005. Abdominal emergencies in cattle. Vet. Clin. North Am. Food Anim. Pract. 21:655-696.

Watts, S. A., and K. W. Clarke. 2000. A survey of bovine practitioners' attitudes to pain and analgesia in cattle. Cattle Pract. 8:361-362.

Weary, D. M., J. M. Huzzey, and M. A. G. von Keyserlingk. 2009. Board-Invited Review: Using behavior to predict and identify ill health in animals. J. Anim. Sci. 87:770-777.

Wittek, T., K. Tischer, T. Gieseler, M. Fürll, and P. D. Constable. 2008. Effect of preoperative administration of erythromycin or flunixin meglumine on postoperative abomasal emptying rate in dairy cows undergoing surgical correction of left displacement of the abomasum. J. Am. Vet. Med. Assoc. 232:418-423. 